\title{
Highly accurate random DNA sequencing using inherent interlayer potential traps of bilayer $\mathrm{MoS}_{2}$ nanopores
}

\section{Payel Sen, Hiofan Hoi, Dipanjan Nandi, Manisha Gupta*}

Payel Sen

Department of Chemical and Materials Engineering

University of Alberta

Edmonton, Canada

Email: payel@ualberta.ca

Hiofan Hoi

Department of Chemical and Materials Engineering

University of Alberta

Edmonton, Canada

Email: hiofan@ualberta.ca

Dipanjan Nandi

Department of Electrical and Computer Engineering

University of Alberta

Edmonton, Canada

Email:dipanjan@ualberta.ca

Manisha Gupta

Department of Electrical and Computer Engineering

University of Alberta

Edmonton, Canada

Email:mgupta1@ualberta.ca 


\begin{abstract}
Solid-state $\mathrm{MoS}_{2}$ nanopores are emerging as potential real-time DNA sequencers due to their ultrathinness and pore stability. One of the major challenges in determining random nucleotide sequence (unlike polynucleotide strands) is the non-homogeneity of the charge interaction and velocity during DNA translocation. This results in varying blockade current for the same nucleotide, reducing the sequencing confidence. In this work, we studied the inherent impedancetunability (due to vertical interlayer potential gradient and ion accumulation) of multilayered $\mathrm{MoS}_{2}$ nanopores along with its effect on improving analyte capture and charge interaction, for more sensitive and confident sensing. Experimentally we demonstrate that 2-3 $\mathrm{nm}$ diameter bilayer $\mathrm{MoS}_{2}$ pores are best suited for high accuracy ( $\left.\sim 90 \%\right)$ sequencing of mixed nucleotides with signalto-noise-ratio greater than 11 in picomolar concentration solutions. High temporal resolution demonstrated by bilayer $\mathrm{MoS}_{2}$ nanopores can help detect neutral proteins in future. The high accuracy detection in low concentration analyte can hence be applied for control and prevention of hereditary diseases and understanding health effects of rare microbial strains.
\end{abstract}

Keywords: DNA sequencing, $\mathrm{MoS}_{2}$ nanopore, label-free, picomolar concentration, nanopore sensitivity 


\section{Introduction}

Accurate DNA sequencing can determine genetic susceptibility to hereditary diseases and determine health effects of a microbial strain. Nanopore sequencing introduced in late 1900s was one of the key breakthrough technologies for DNA sequencing due to its real-time, low-cost, longread, label-free and amplification-free sensing approach ${ }^{1}$. Biological nanopores have been extensively used for sequencing because they facilitate slow DNA translocation, favourable for highly resolved sensing. However, they lack longevity and thermomechanical stability ${ }^{2}$, leading to the development of solid-state nanopores. Solid-state nanopores are commonly fabricated on insulating membranes like silicon nitride $\left(\mathrm{SiN}_{\mathrm{x}}\right)$ or silicon dioxide $\left(\mathrm{SiO}_{2}\right)$ by transmission electron microscopy or helium ion microscopy ${ }^{3-7}$. Solid-state nanopores offer the advantage of being stable even though they suffer from high velocity of DNA translocation ${ }^{2}$. In sequencing, analyte DNA molecules are electrophoretically driven through the nanopore and are electrically detected via the ionic current change caused during their passage through the nanopore. Particularly in DNA, each nucleotide (nt) base (adenine, thymine, cytosine, and guanine) can produce distinguishable ionic blockade currents because of the difference in their size and surface charge ${ }^{6-9}$. The characteristic current drops obtained can therefore identify the order of nucleotides, which can be used towards determining the whole DNA sequence ${ }^{3}$. Nanopore sequencing method is often prone to missing individual or few nucleotides leading to erroneous sequence. Sensitivity and the sensing accuracy depend upon the analyte concentration which influences the capture rate, the translocation velocity which decides the residence time in the pore and the nanopore geometry and material which governs the pore conductance. Hence, designing a pore and the measurement setup are very 
important for measurement of low concentration analyte detection with high accuracy and sensitivity.

Using nanopore technology, DNA can be sequenced with improved accuracy without the need for amplification techniques like Polymerase Chain Reaction $(\mathrm{PCR})^{10}$. However, the probability of DNA occurring in the nanopore capture volume reduces with low sample concentration and pore volume. Achieving a good detection rate and accuracy at picomolar DNA concentrations thus requires optimized surface charge interaction around the nanopore. Few works have been performed to improve sensing efficiency at low concentration ${ }^{11-13}$. Pathogen identification and DNA oligo sensing by Surface Enhanced Raman Spectroscopy has been performed ${ }^{11-12}$. Low concentration analyte detection has been achieved by employing additional techniques like dielectrophoretic (DEP) trapping to increase the electrophoretic pull exerted on the molecular strand to be sensed ${ }^{13}$. The traps help in regulating nanopore volume in a range comparable to the translocating molecules and also increases the capture rate. DEP trapping has been used to sense single nucleotides at a concentration as low as $5 \mathrm{fM}^{13}$. However, these techniques require additional process aids making it more complex. Usually DNA concentrations in micromolar to nanomolar range are employed for solid-state nanopore sequencing ${ }^{14-19}$. In this work we aim at introducing a simple and repeatable approach towards picomolar concentration DNA sequencing by exploiting properties of a suitable membrane material. Thus, one can conduct DNA profiling of dilute samples collected from crime scenes $(50 \mathrm{ng} / \mu \mathrm{L} \text { to } 0.023 \mathrm{ng} / \mu \mathrm{L})^{20}$, archaeological sites (4$17 \mathrm{ng} / \mu \mathrm{L})^{21}$ and even for rare pathogen strain analysis ${ }^{22-23}$, using this technique.

A single dominant mutated gene in each cell can cause harmful health effects. Diseases like cystic fibrosis, sickle-cell anaemia, neurofibromatosis, color-blindness are all caused by point mutations to the genome ${ }^{24-25}$. Identification of single nucleotide mutation can be done if accurate DNA 
sequence of the mutated gene can be obtained. The mutated sequence can then be compared with wild gene to identify the mutation. This identification of mutated gene can thereby help in early detection of life-threatening diseases. Sensing (blockade current) resolution can be along the space (obtaining current blockades specific to individual bases) and time regime (obtaining high dwell time of each base inside the nanopore $)^{9,24}$. The current blockade depends on the fraction of the nanopore volume occupied by the analyte at any time instant. In other words, the nanopore volume should be comparable to single nucleotide size to sense individual species. Single nucleotide is 1.6 - $1.8 \mathrm{~nm}$ long and $\sim 1 \mathrm{~nm}$ in diameter ${ }^{26}$. Therefore, $2-4 \mathrm{~nm}$ diameter nanopores on $\sim 1.5-2 \mathrm{~nm}$ thin membrane should show good nucleotide sensing resolution. Silicon nitride $\left(\mathrm{SiN}_{\mathrm{x}}\right)$ is one of the most studied nanopore materials till date, especially due to stability and compatibility with standard fabrication techniques ${ }^{27}$. However, higher thickness of the membranes $(20-50 \mathrm{~nm})$ compared to molecular dimensions $(\sim 1 \mathrm{~nm})$, limits spatial resolution. $\mathrm{SiN}_{\mathrm{x}}$ membranes thinner than $5 \mathrm{~nm}$ have more chances of pits in them, making it difficult to reduce the thickness of the membranes beyond this ${ }^{28}$. In two-dimensional (2D) materials the layers are separated by weak van der Waals forces, which help obtain stable, monolayer thickness control. 2D material nanopores, having a small control volume can therefore be utilized for developing nanopores with geometry desired for single nucleotide detection ${ }^{29}$. Nanopores on molybdenum disulphide $\left(\mathrm{MoS}_{2}\right)$, a type of 2D metal dichalcogenide, have proved to be promising DNA sequencers for their structural stability in aqueous medium, high signal-to-noise ratio and no sticking of $\mathrm{DNA}^{14}$. The abundance of Molybdenum (Mo) around $\mathrm{MoS}_{2}$ pore offers favorable analyte/pore wall surface charge interactions and minimizes noise, making it a good alternative for nanopore fabrication ${ }^{14,30-32}$.

There are limited number of studies on single nucleotide sensing using 1-layer thick $\mathrm{MoS}_{2}$ nanopores ${ }^{33-37}$. Single nucleotide detection from homogenous polynucleotide strands has been 
demonstrated by 1-layer thick $\mathrm{MoS}_{2}$ nanopores at a concentration of $5 \mu \mathrm{g} \mathrm{ml}^{-1}$ with $100 \mathrm{mM} \mathrm{KCl}$ solution $^{14}$. In this work, we have demonstrated single nucleotide sequencing from DNA template containing customized random nucleotide sequence, which demands slower translocation for enhanced surface charge interaction along nucleotide/pore interface. 1-layer thick $\mathrm{MoS}_{2}$ makes DNA translocation very fast hampering temporal resolution. One of the major reasons for this is the thickness of 1-layer $\mathrm{MoS}_{2}$ is $0.65 \mathrm{~nm}$, which is less than single nucleotide size $(1.6-1.8 \mathrm{~nm})$. This compromises charge interaction making DNA translocation fast, thus limiting temporal resolution. Research has been carried out to reduce speed of translocation by introducing viscosity gradient between cis and trans electrolytic chambers ${ }^{38-42}$. In this work, we explore the inherent ability of multilayer (2 - 6 layers thick) $\mathrm{MoS}_{2}$ having thickness in the range of $1-4 \mathrm{~nm}$, in slowing DNA translocation. Additionally, the behavior of 1-layer and multilayer thick $\mathrm{MoS}_{2}$ differs under a vertical electrical field imposed by two electrodes dipped in cis and trans chambers. In multilayer $\mathrm{MoS}_{2}$, the strong interlayer coupling creates a potential gradation along the van der Waals separated layers, as each layer experiences a different electric potential ${ }^{43}$. This potential gradient causes trapping and detrapping of the phosphate groups of DNA strand with the Molybdenum atoms at the nanopore. The increased negative-positive charge interaction creates an additional electrophoretic pull ${ }^{43-44}$. This can provide a platform for effective capture and detection of molecules at sub-nanomolar molecular concentrations without using any external trapping mechanism. Thus, by tuning the number of layers of $\mathrm{MoS}_{2}$ we can control the velocity and the conductance of the pore.

This work primarily focuses on determining $\mathrm{MoS}_{2}$ nanopore properties suitable for label-free sensing of nucleotides from a DNA template containing mixed nucleotides at low (picomolar) concentration with a good detection rate and resolution. Picomolar concentration used for sensing 
exploits the amplification-free aspect of nanopore sensing enabling high-accuracy, low-cost rare DNA fingerprinting. COMSOL Multiphysics 5.4 simulation followed by experimental recordings were performed for a stepwise optimization of number of layers suitable for a highly repeatable and efficient DNA nucleotide sensing. Here, we have demonstrated both via simulations and experiments that the 2-layers thick $\mathrm{MoS}_{2}$ nanopores are better suited for improving detection sensitivity and accuracy for low (picomolar) concentration analytes.

\section{Results and discussions}

\section{Optimization of the number of $\mathrm{MoS}_{2}$ layers for single nucleotide detection}

DNA translocation through $1-10 \mathrm{~nm}$ diameter pores was first simulated using COMSOL Multiphysics 5.4, for different membrane types: 1 - 6 layers $\mathrm{MoS}_{2}\left(0.65-4 \mathrm{~nm}\right.$ thick), $50 \mathrm{~nm} \mathrm{SiN}_{\mathrm{x}}$ and 76 - layers $\mathrm{MoS}_{2}$ having thickness $\left(49.4 \mathrm{~nm}\right.$ ) similar to that of $\mathrm{SiN}_{\mathrm{x}}$ membrane. A 2D symmetric geometry representing two electrolyte $(300 \mathrm{mM} \mathrm{KCl})$ filled half-cells separated by a pore bearing membrane was considered, similar to the experimental setup used as shown in Figure S5 in Supplementary information. DNA was modelled as a $10 \mathrm{~nm}$ long homogenous rectangular poly-nucleotide strand and was introduced in the cis chamber with a trans bias ranging from -200 to $200 \mathrm{mV}$ to pull the DNA through the nanopore. Figure 1.a provides a schematic representation of the force balance conducted on the DNA for simulating blockade conductance and translocation kinetics. Detailed information on modelling geometry (Figure S1 of Supplementary information), meshing parameters and physics are discussed in Supplementary information. Figure S2 shows the 3D revolved geometry with the potential gradient profile for different number of $\mathrm{MoS}_{2}$ layers and $50 \mathrm{~nm}$ thick $\mathrm{SiN}_{\mathrm{x}}$ pores. 
The ionic conductance of these solid-state pores is first simulated for an electrolyte $(\mathrm{KCl})$ concentration of $300 \mathrm{mM}$ and $-200 \mathrm{mV}$ to $200 \mathrm{mV}$ trans bias range, while keeping the cis chamber grounded. Figure 1.b shows the variation of ionic conductance with pore diameter for different types of membranes. The cross-over diameter mentioned in Figure 1.b is found to decrease with increase in number of $\mathrm{MoS}_{2}$ layers. Cross-over point 1 occurs between 1-layer and 2-layers thick $\mathrm{MoS}_{2}$ at $2 \mathrm{~nm}$ pore diameter. This necessarily states that ionic conductance better for a 2 - layers thick $\mathrm{MoS}_{2}$ pore as compared to the 1-layer thick $\mathrm{MoS}_{2}$ pore for diameters greater than $2 \mathrm{~nm}$. Table 1 quantitatively lists the simulated ionic conductance for different thickness $\mathrm{MoS}_{2}$ and 50 nm thick $\mathrm{SiN}_{\mathrm{x}}$ nanopores, with the corresponding I-V displayed in Figure 1.b. 


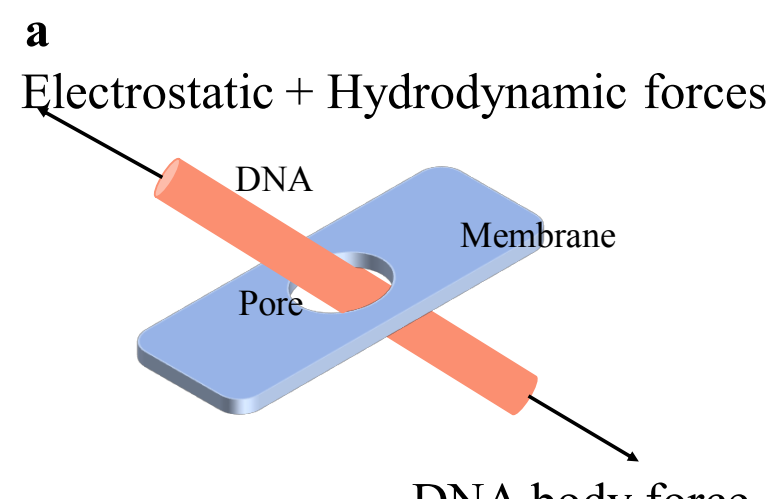

b
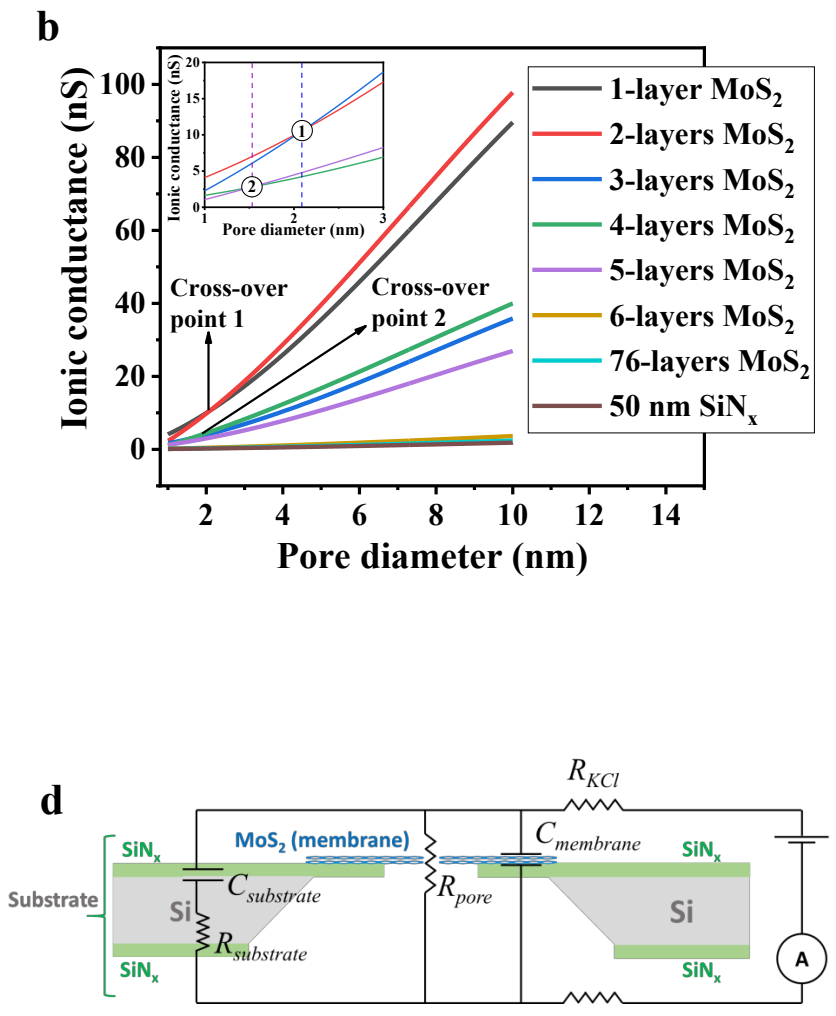

DNA body force

c

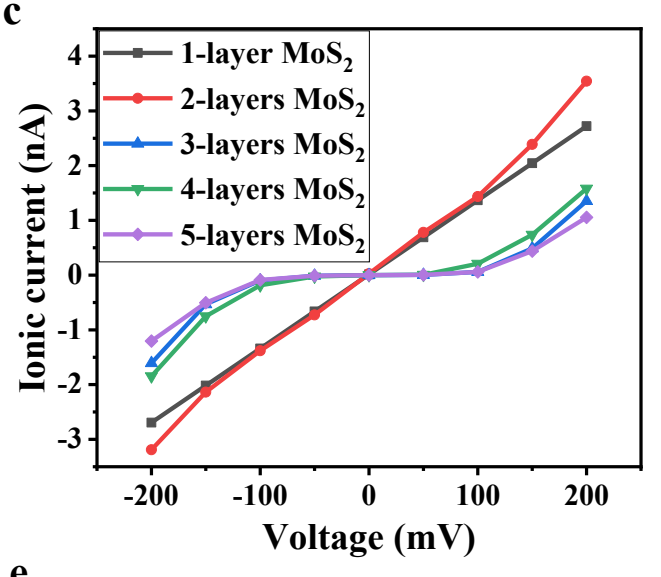

e

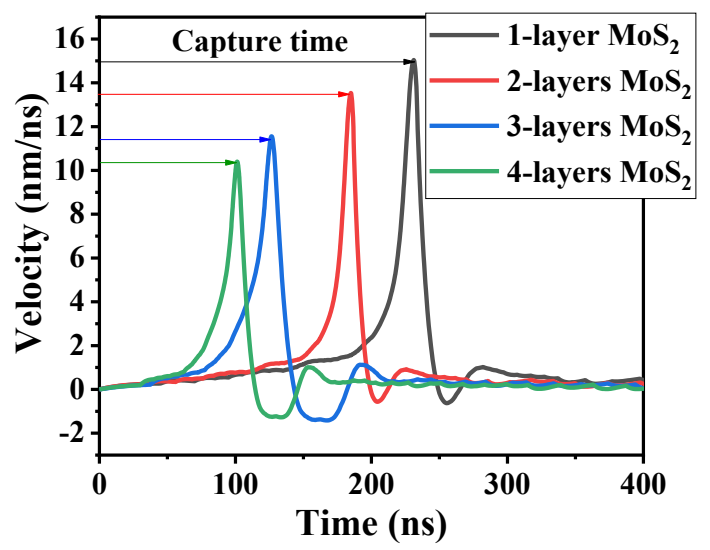

Figure 1. a. Simple schematic representation of the force balance used for simulating DNA translocation electrokinetics through nanopores, b. Simulated ionic conductance of 1-6 layers $\mathrm{MoS}_{2}$ (thickness range: 0.65-4 nm), $50 \mathrm{~nm}$ thick $\mathrm{SiN}_{\mathrm{x}}$ and 76-layers $\mathrm{MoS}_{2}$ (thickness: $49.4 \mathrm{~nm}$ ), showing cross-over points, Cross-over 1 indicates the diameter beyond which ionic conductance for 2-layers thick $\mathrm{MoS}_{2}$ nanopore is higher than 1-layer thick $\mathrm{MoS}_{2}$. Similarly, above cross-over point 2, the ionic conductance through 4 - layers thick $\mathrm{MoS}_{2}$ pore is found to be greater than that 
for 3-layers thick $\mathrm{MoS}_{2}$; inset showing the cross-over points clearly: data reported for $-200 \mathrm{mV}$ to $200 \mathrm{mV}$ trans bias and $300 \mathrm{mM} \mathrm{KCl}$ c. Simulated I-V profile for 1- 4 layers thick $\mathrm{MoS}_{2}$ (shortlisted from ionic conductance comparison) for $2.5 \mathrm{~nm}$ pore diameter (greater than cross-over point 1), showing highest non-linearly varying I-V response demonstrated by 2-layers thick $\mathrm{MoS}_{2}$ : simulation conducted for $-200 \mathrm{mV}$ to $200 \mathrm{mV}$ bias range and $300 \mathrm{mM} \mathrm{KCl}$, d. Representative nanopore circuit showing the active capacitance and resistances, e. Simulated translocation velocity profile of $10 \mathrm{~nm}$ poly-guanine strand through 1-4 layers thick $\mathrm{MoS}_{2}$ nanopores of $2.5 \mathrm{~nm}$ diameter, showing the capture time and velocity profile for each pore: data reported for $200 \mathrm{mV}$ bias and $100 \mathrm{mM} \mathrm{KCl}$.

Table 1: Simulation results for drawing an ionic conductance-based comparison between different type of nanopores (1 - 6 layers thick $\mathrm{MoS}_{2}, 76$ - layers thick $\mathrm{MoS}_{2}$ and $50 \mathrm{~nm}$ thick $\mathrm{SiN}_{\mathrm{x}}$ ) for 200 $\mathrm{mV}$ bias and $300 \mathrm{mM} \mathrm{KCl}$. The ionic conductance for different nanopore types having $2.5 \mathrm{~nm}$ diameter are listed. The diameters at cross-over points 1 and 2 (extracted from Figure 1.b) are also numerically mentioned below.

\begin{tabular}{|c|c|c|c|}
\hline Nanopore type & Membrane thickness & Cross-over points & Ionic conductance \\
\hline 1-layer thick $\mathrm{MoS}_{2}$ & $0.65 \mathrm{~nm}$ & \multirow[t]{2}{*}{ Point 1: $2 \mathrm{~nm}$ diameter } & $13.48 \mathrm{nS}$ \\
\hline 2-layers thick $\mathrm{MoS}_{2}$ & $1.3 \mathrm{~nm}$ & & $14.12 \mathrm{nS}$ \\
\hline 3-layers thick $\mathrm{MoS}_{2}$ & $1.9 \mathrm{~nm}$ & \multirow{2}{*}{ Point 2: $1.5 \mathrm{~nm}$ diameter } & $5.39 \mathrm{nS}$ \\
\hline 4-layers thick $\mathrm{MoS}_{2}$ & $2.6 \mathrm{~nm}$ & & $6.33 \mathrm{nS}$ \\
\hline 5-layers thick $\mathrm{MoS}_{2}$ & $3.8 \mathrm{~nm}$ & \multirow{2}{*}{ 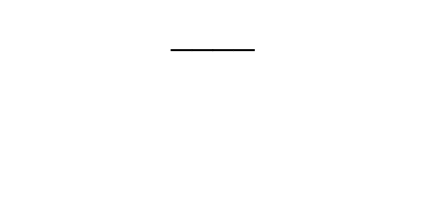 } & $4.05 \mathrm{nS}$ \\
\hline 6-layers thick $\mathrm{MoS}_{2}$ & $5.2 \mathrm{~nm}$ & & $0.57 \mathrm{nS}$ \\
\hline
\end{tabular}




\begin{tabular}{|c|c|c|c|}
\hline 76-layers thick $\mathrm{MoS}_{2}$ & $49.4 \mathrm{~nm}$ & - & $0.37 \mathrm{nS}$ \\
\hline $50 \mathrm{~nm}$ thick $\mathrm{SiN}_{\mathrm{x}}$ & $50 \mathrm{~nm}$ & - & $0.28 \mathrm{nS}$ \\
\hline
\end{tabular}

The I-V behaviour for the selected 1- 4 layers thick $\mathrm{MoS}_{2}$ pores with applied bias from $-200 \mathrm{mV}$ to $200 \mathrm{mV}$ in $300 \mathrm{mM} \mathrm{KCl}$ was then simulated. 1-layer thick $\mathrm{MoS}_{2}$ pores demonstrate a linear IV curve as compared to the 2 - 4 layers thick $\mathrm{MoS}_{2}$ pores show non-linear behaviour (see Figure 1.c). It was found that $\mathrm{I}-\mathrm{V}$ profile becomes more non-linear with increasing number of layers. The ionic conductance trend and I-V response (Figure 1.b-c) observed by COMSOL Multiphysics simulation can be best explained by utilising a Resistance $(\mathrm{R})$ - Capacitance $(\mathrm{C})$ equivalent model for the nanopore (Figure 1.d). The nanopore acts as a resistance $(\mathrm{R})$ and membrane along with the electrolyte is the capacitance $(\mathrm{C})$. The current variation with respect to resultant impedance $(\mathrm{Z})$ can therefore be studied (see Equation $1^{[45]}$ ).

$$
Z^{2}=R^{2}+\frac{1}{(\omega C)^{2}}, \text { where, } \omega \text { is the phase change. }
$$

The Cross-over points 1 and 2 indicate the diameters above which the capacitance is dominant as compared to the pore resistance, which reduces the impedance, thus causing a rise in ionic conductance. It is also important to note that this behaviour is highly dependent on the applied bias (greater than $50 \mathrm{mV}$ in this case as seen in Figure 1.c). In case of 1-layer thick $\mathrm{MoS}_{2}$, the pore resistance dominates the impedance producing a linear I-V (Figure 1.c). For smaller pores $(\sim 1-2$ $\mathrm{nm}$ diameter), due to higher pore resistance, the impedance increases, thus reducing the ionic current (Figure 1.c). With increase in the number of layers, an interlayer potential gradient along the $\mathrm{MoS}_{2}$ interfaces causes accumulation of ions therefore producing a capacitance ${ }^{[45-46]}$. Hence, the resultant impedance has a contribution from the membrane-based interlayer and intralayer 
charge storage, electro-activity caused by pseudo-capacitance and the pore resistance ${ }^{[45-46]}$. As a result, an increase in $\mathrm{I}-\mathrm{V}$ is observed above a certain applied voltage indicating an increased conductance (Figure 1.c).

To understand sensing performance of $\mathrm{SiN}_{\mathrm{x}}$ and multilayer $\mathrm{MoS}_{2}$ nanopores, the kinetics for translocation of the same analyte DNA were then simulated using $100 \mathrm{mM} \mathrm{KCl}$ electrolyte. The results show that increase in number of $\mathrm{MoS}_{2}$ layers shortens nucleotide capture time and improves dwell time of the nucleotides at the nanopore (as depicted by lower peak velocity). Figure 1.e shows the translocation velocity profile of homogenous poly-guanine strand through 1-4 layers thick $\mathrm{MoS}_{2}$ nanopores. Increased capture rate and longer pore dwell times suggest an improved event rate, sensitivity and better temporal resolution (slower translocation). Higher capture rate and dwell times displayed by 2 and 4-layers thick $\mathrm{MoS}_{2}$ pores can therefore be directly related to their sensing efficiency. Figure S3 and Figure S4 of Supplementary information respectively shows the conductance blockades and translocation velocity profiles of different poly-nucleotide strands.

\section{Experimental considerations based on simulated optimizations}

To verify our simulation results, we fabricated multiple $\mathrm{MoS}_{2}$ nanopores with different number of layers, the procedure of fabrication is explained in detail in the experimental details section. Since, the highest crossover pore diameter observed in ionic conductance simulation for 1-4 layers $\mathrm{MoS}_{2}$ (Table 1) was above $2 \mathrm{~nm}$, pores of diameter around $2.5 \mathrm{~nm}$ were fabricated by Scanning Transmission Electron Microscopy (STEM). Based on the simulation results, we decided to fabricate and experimentally study 2-layers and 4-layers thick $\mathrm{MoS}_{2}$ pores to utilize their higher ionic conductance (as seen in Figure 1.b-c). Experiments were conducted with these pores using 
low $(\sim 40 \mathrm{pM})$ concentration of analyte DNA solution to verify the improved sensitivity (Figure 1.e),

\section{$\mathrm{MoS}_{2}$ membrane and nanopore fabrication and characterization}

Free-standing mechanically exfoliated $\mathrm{MoS}_{2}$ membranes on $\mathrm{SiN}_{\mathrm{x}}$ support were characterized by Raman Spectroscopy and High-Resolution Transmission Electron Microscopy (HRTEM) to determine the number of layers of $\mathrm{MoS}_{2}$. Nanopores fabricated on 2- and 4-layer thick $\mathrm{MoS}_{2}$ were then used for all the other experiments. STEM diffractogram is very accurate for detection of the number of $\mathrm{MoS}_{2}$ layers but cannot be used for more than 3 layers. Hence, Raman shift was used to determine 4 - layers thick $\mathrm{MoS}_{2}$. Figure 2.a shows the STEM image and diffractogram of a typical exfoliated free-standing 2-layers thick $\mathrm{MoS}_{2}$ membrane. Figure 2.b represents Raman spectrum of a typical 4-layer thick $\mathrm{MoS}_{2}$ membrane showing a Raman shift of $23.9 \mathrm{~cm}^{-1}$, which confirms the number of layers. 


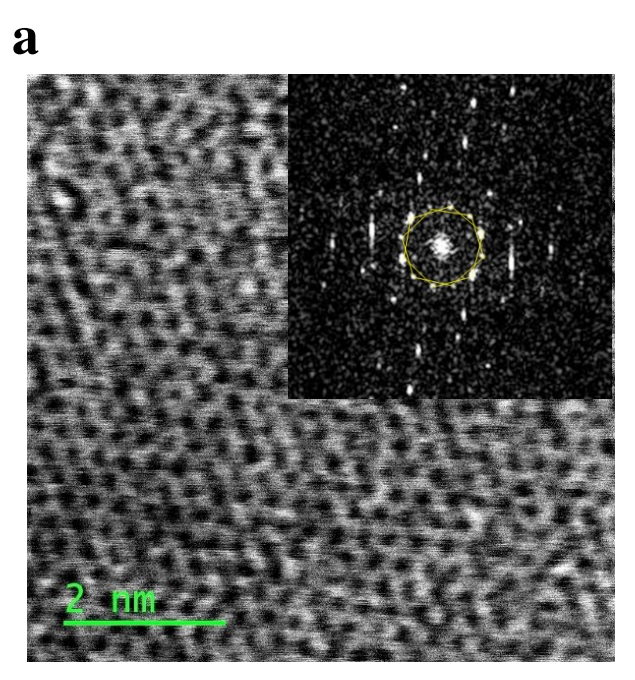

c

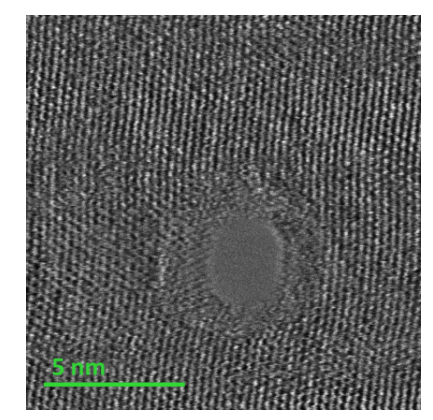

e

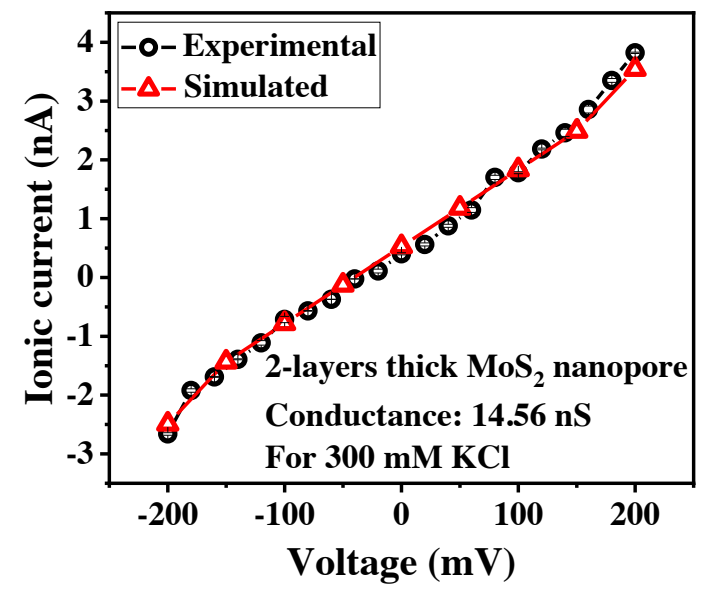

b

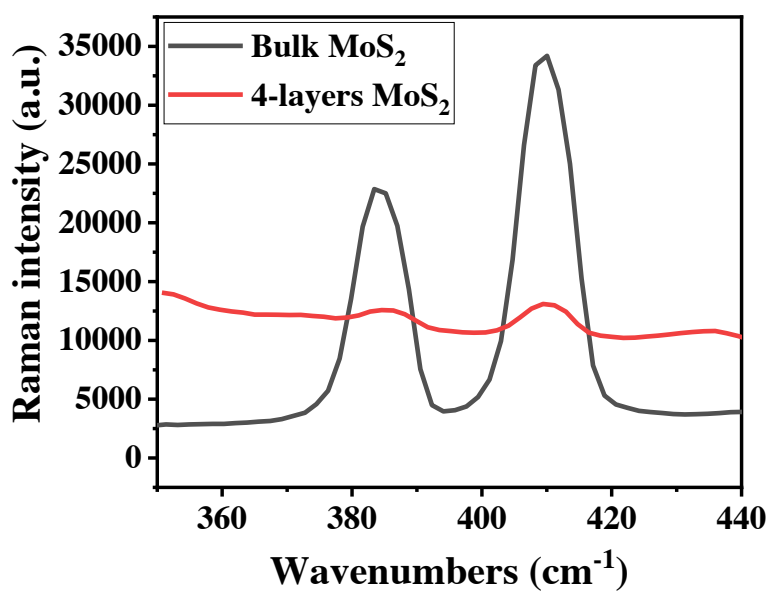

d

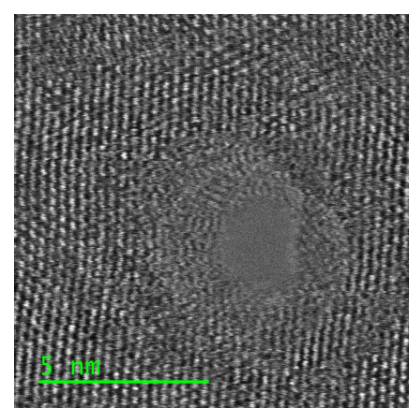

f

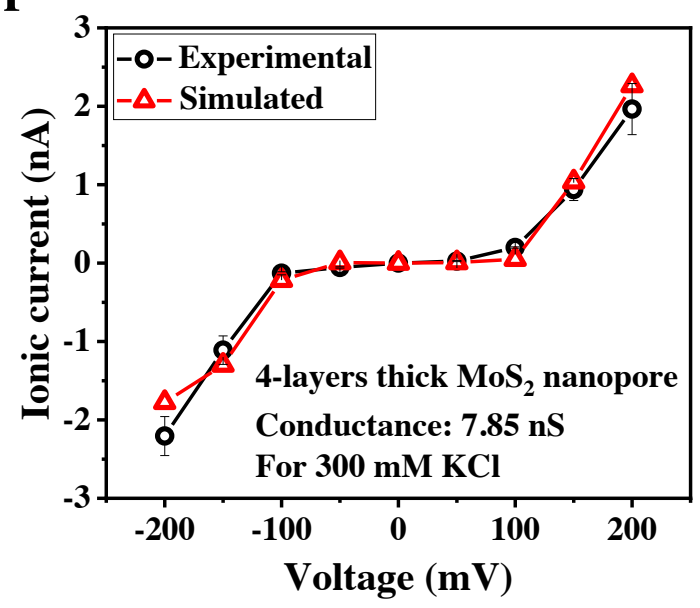

Figure 2. a. HRTEM characterization of 2-layers thick $\mathrm{MoS}_{2}$ membrane with inset diffractogram showing two overlapped hexagons confirming 2 - layers $\mathrm{MoS}_{2}$, b. Raman Spectroscopic profile of a representative exfoliated 4 - layers thick $\mathrm{MoS}_{2}$ membrane shows two vibrational modes: intralayer (mainly chemical composition dependent) and inter-layer (large influence by mass and hence number of layers); two peaks at $383 \mathrm{~cm}^{-1}$ and $408 \mathrm{~cm}^{-1}$ are fingerprints of bulk $\mathrm{MoS}_{2}$; the peak 
distance of $23.9 \mathrm{~cm}^{-1}$ indicates that it consists of 4 layers, c. TEM images of STEM fabricated nanopores on 2-layers thick $\mathrm{MoS}_{2}$ and d. TEM images of STEM fabricated nanopores on 4-layers thick $\mathrm{MoS}_{2}$ membranes, e. Experimental and simulated I-V profiles (using $300 \mathrm{mM} \mathrm{KCl}$ ) through 2-layers thick $\mathrm{MoS}_{2}$ predicting a $2.5 \mathrm{~nm}$ pore diameter and f. Experimental and simulated I-V profiles (using $300 \mathrm{mM} \mathrm{KCl}$ ) through 4-layers thick $\mathrm{MoS}_{2}$ pores predicting a $2.8 \mathrm{~nm}$ pore diameter by experimental and simulated pore conductance comparison; error bars in e-f represents error between multiple conductance experiments.

Nanopores were fabricated using STEM on 2 and 4-layers thick $\mathrm{MoS}_{2}$, HRTEM images of which are shown in Figure 2.c-d respectively. Ionic current through the fabricated nanopores was measured by sweeping the voltage from $-200 \mathrm{mV}$ to $200 \mathrm{mV}$ and their conductance was then extracted. Each pore was measured 8 times to obtain a stable conductance after repeated cleaning between every measurement, and the average conductance starting from the third measurement was reported. Conductance of 2 and 4-layers thick $\mathrm{MoS}_{2}$ nanopore were measured to be $\sim 14.56 \mathrm{nS}$ and $\sim 7.85 \mathrm{nS}$ respectively. We used our simulation results for this conductance to predict the pore diameters as $2.5 \mathrm{~nm}$ and $2.8 \mathrm{~nm}$ for the 2 and 4 - layers thick $\mathrm{MoS}_{2}$ pores respectively. Figure 2.ef shows the fitted experimental and simulated I-V graphs for the predicted pore diameters.

\section{DNA sequencing at picomolar concentration (pM) using 2-layers and 4-layers $\mathrm{MoS}_{2}$ nanopores}

Once the pores conductance was characterised, DNA translocation experiments were conducted on the same pores. For the DNA translocation experiments, we have used a $40 \mathrm{pM}$ solution of single-stranded (ss) DNA oligos containing 30 mixed nucleotides as described in the experimental details section. A bias of $200 \mathrm{mV}$ was used to measure the ionic current of DNA translocation through the 7 fabricated pores each, for 2 and 4-layers thick $\mathrm{MoS}_{2}$ having diameters in the range 
of $2.5-3 \mathrm{~nm}$. The measurement results were then used to determine the efficiency and accuracy of the order and count of nucleotides present in the DNA strand.

The recorded translocation profile was analysed to obtain current drop and dwell times. Figure 3.a shows distinct single nucleotide peaks obtained by sequencing through 2-layers thick $\mathrm{MoS}_{2}$ nanopores. Figure 3.b shows DNA translocation peaks through 4-layers thick $\mathrm{MoS}_{2}$ nanopores showing simultaneous detection of multiple nucleotides. Figure 3.c-d show 4-layers thick $\mathrm{MoS}_{2}$ demonstrating higher dwell times and lower current drops compared to 2-layers thick $\mathrm{MoS}_{2}$ pores, which agrees with our simulation results. Figure 3.c-d also shows the ability of 2-layers thick $\mathrm{MoS}_{2}$ pore for detection of single-nucleotide with well-defined and distinct current levels for different nucleotides whereas the 4-layers thick $\mathrm{MoS}_{2}$ pore demonstrates overlapped current signatures for different nucleotides. Thus, it can clearly be seen that the number of layers of $\mathrm{MoS}_{2}$ very strongly decide the sensitivity of a pore with 2-layers thick pores showing the best results in terms of single nucleotide detection. 
a
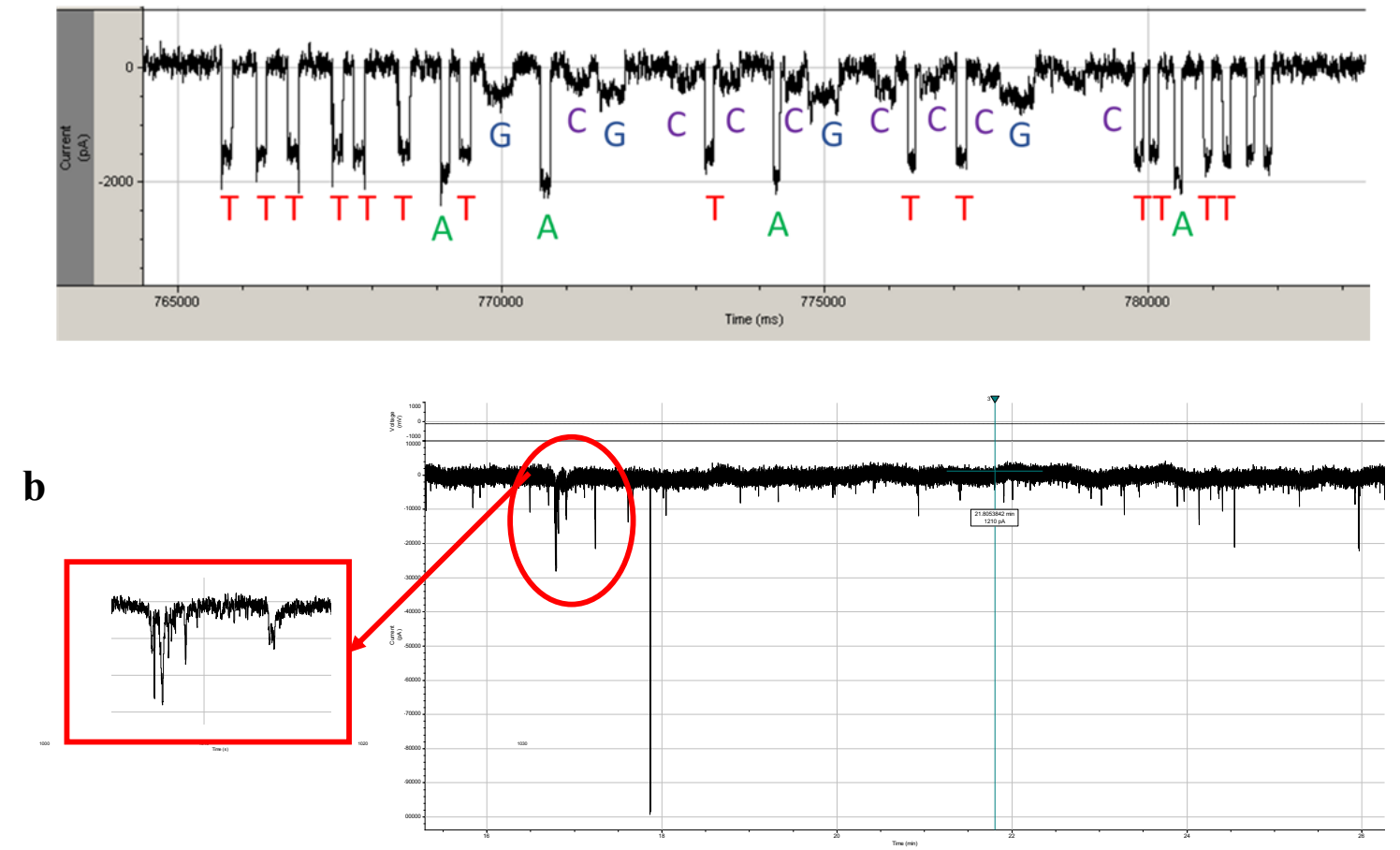

c

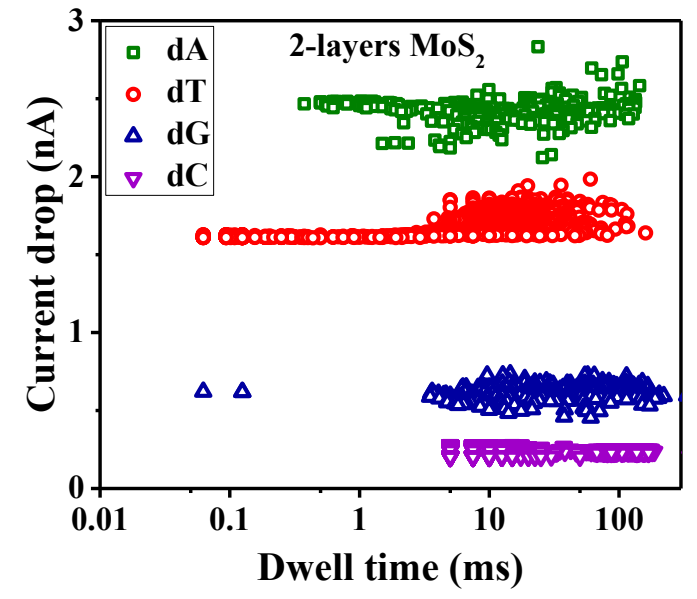

d

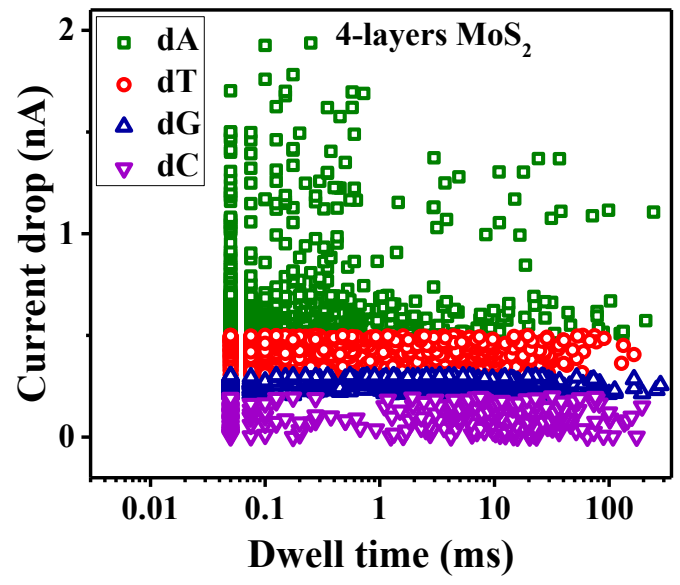

Figure 3. a. Characteristic current blockades for individual nucleotides obtained from ssDNA translocation through $2.5 \mathrm{~nm}$ diameter pore on 2-layers thick $\mathrm{MoS}_{2}$, b. A typical truncated ssDNA translocation profile through $2.8 \mathrm{~nm}$ diameter 4-layers thick $\mathrm{MoS}_{2}$ pore showing single nucleotide and multiple nucleotide detection peaks, c. Current drop vs dwell time plot for $>3000$ base $(60$ min) translocation through 2-layers thick $\mathrm{MoS}_{2}$ : showing distinct current levels of 2.4 $\pm 0.08 \mathrm{nA}$, $1.67 \pm 0.06 \mathrm{nA}, 0.62 \pm 0.05 \mathrm{nA}$ and $0.24 \pm 0.03 \mathrm{nA}$ for $\mathrm{dA}, \mathrm{dT}, \mathrm{dG}$ and $\mathrm{dC}$ respectively with a signalto-noise ratio $>11$ (comparable to ${ }^{[14,19,47-48]}$ ) and d. Current drop vs dwell time plot for $>3000$ 
base translocation through 4-layers thick $\mathrm{MoS}_{2}$ : showing huge overlapping of current levels for different nucleotides; blockade currents obtained being $0.86 \pm 0.33 \mathrm{nA}$ for $\mathrm{dA}, 0.5 \pm 0.09 \mathrm{nA}$ for $\mathrm{dT}, 0.29 \pm 0.07 \mathrm{nA}$ for $\mathrm{dG}$ and $0.1 \pm 0.06 \mathrm{nA}$ for $\mathrm{dC}(\mathrm{dA}$ : Adenine, $\mathrm{dT}$ : Thymine, $\mathrm{dG}$ : Guanine, $\mathrm{dC}$ : Cytosine).

\section{Detection rate and sensing efficiency}

Table 2 shows dwell times demonstrated by 2- and 4-layers thick $\mathrm{MoS}_{2}$ nanopores for $60 \mathrm{~min}$ translocation, as extracted from Figure 3.c-d. 2-layers thick $\mathrm{MoS}_{2}$ successfully retards the translocation to $\sim 67$ nucleotides per minute, resolving single-nucleotide blockade signal with dwell times in the range of $0.05-140 \mathrm{~ms}$. 4-layers thick $\mathrm{MoS}_{2}$ demonstrates dwell time, twice as that shown by 2-layers thick $\mathrm{MoS}_{2}$ pore, as mentioned in Table 2. Dwell times and current drops obtained for both 2-layers and 4-layers thick $\mathrm{MoS}_{2}$ are higher than dwell times reported for 1-layer thick $\mathrm{MoS}_{2}[14,44]$.

Table 2: Simulated and Experimental dwell time for 4-layers and 2-layers thick $\mathrm{MoS}_{2}$ nanopore sensing. It can be clearly observed that there is a discrepancy in the simulated and experimental dwell time, and this can be due to the simulation parameters chosen.

\begin{tabular}{|l|l|l|}
\hline Techniques & Dwell time for 4-layers thick $\mathbf{M o S}_{\mathbf{2}}$ pore & Dwell time for 2-layers thick MoS $\mathbf{2}$ pore \\
\hline Simulation & $0.4-0.7 \mathrm{~ms}$ & $0.19-0.49 \mathrm{~ms}$ \\
\hline Experiment & $0.04-350 \mathrm{~ms}$ & $0.05-140 \mathrm{~ms}$ \\
\hline
\end{tabular}

Few discrepancies are observed in dwell times (see Table 2) between the simulation and experimental studies. These are due to the restrictions imposed on the nanopore system during simulation which are not strictly followed during practical experimental scenario. For example, 
blockade conductance in simulations depend only upon surface charge interaction between pore walls, membrane surface and molecule and on the imposed bias. Also, only vertical translation of the molecule is being considered in this case taking care of the aspect ratio and meshing issues in COMSOL Multiphysics. In experiments the blockade conductance is also influenced by the molecular conformations inside the pore, amplification factor of the tool (amplifier), noise filters, etc, which create the difference. Moreover, simulations are carried out from a distance of $4 \mathrm{~nm}$ away from the pore mouth for a cell size of $100 \mathrm{~nm} \times 100 \mathrm{~nm}$, which differs from the actual molecular trajectory and cell size $(\sim \mathrm{mm})$. Hence, simulations neglect the charge and kinetic interactions for a large distance in and out of the pore, giving rise to difference in results (like dwell time values). 
$\mathbf{a}$
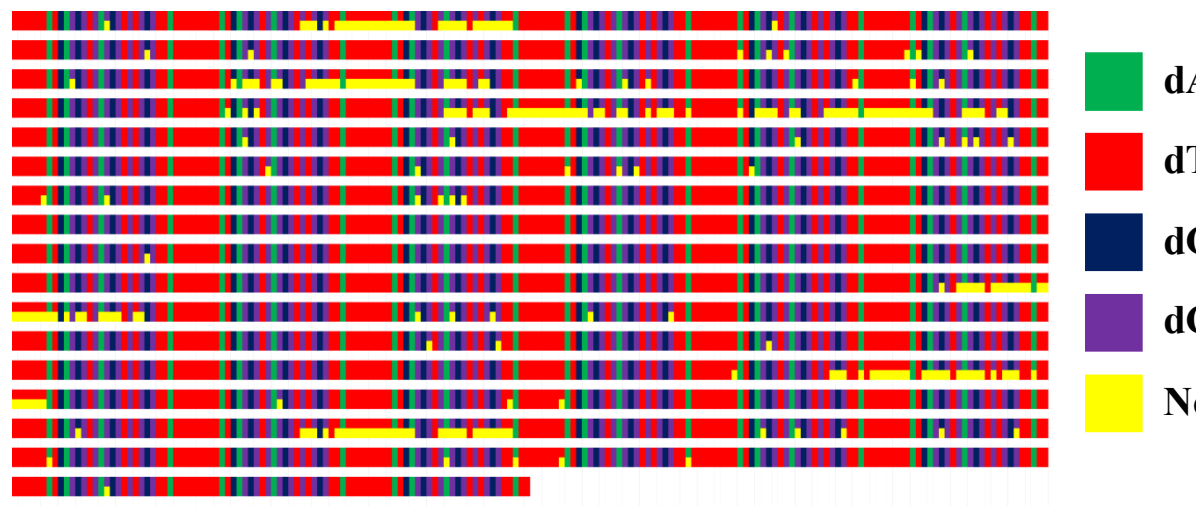

dA

dT

dG

dC

Not detected
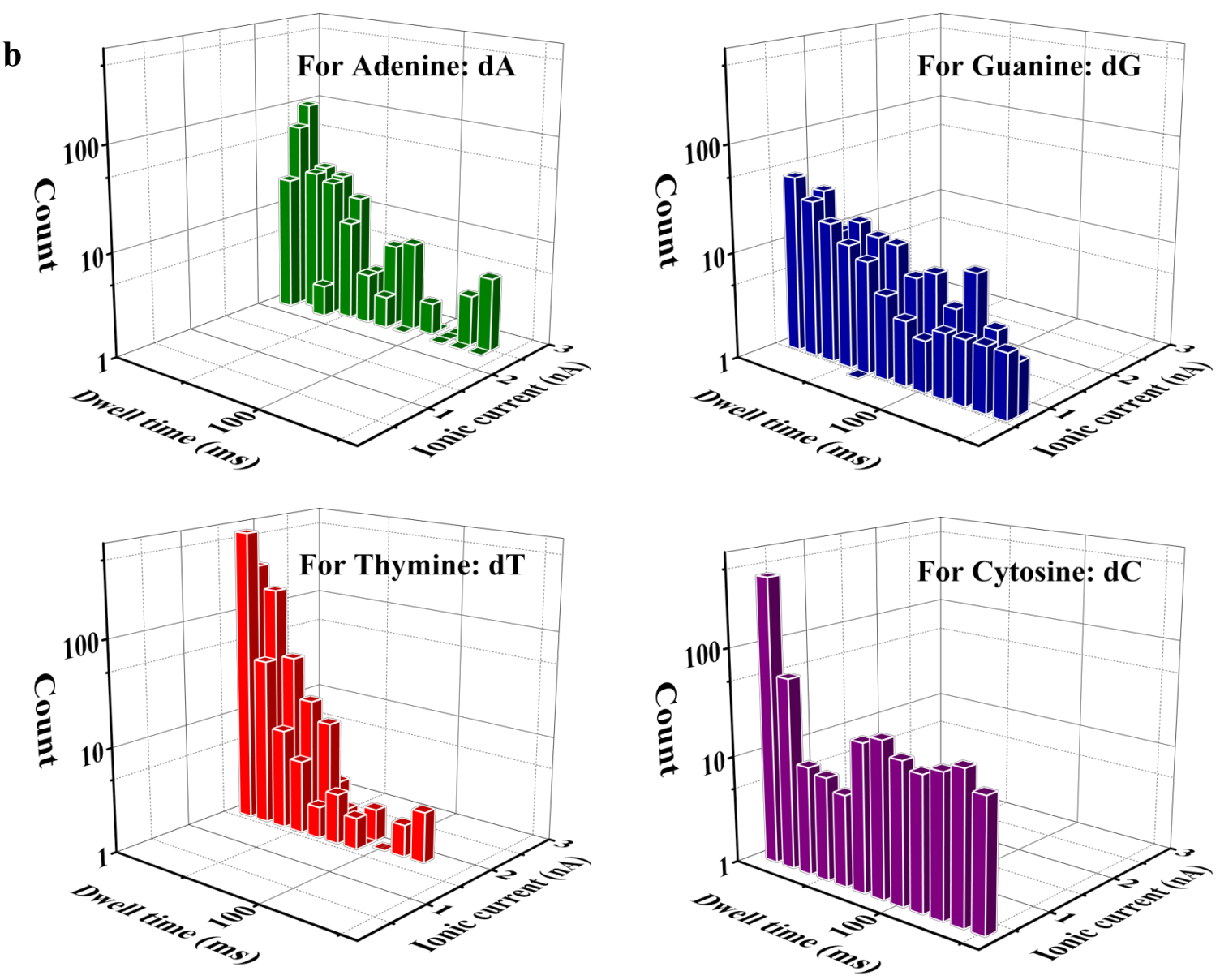

Figure 4. a. DNA sequence sensed through 2-layers thick $\mathrm{MoS}_{2}$ pore showing detected nucleotides: dA (green), dT (red), dG (blue) and dC (purple) and undetected nucleotides (yellow) as compared with the expected sequence, visually representing the process efficiency. It can clearly be seen from the sequence that we have very few nucleotides which were not detected. b. 3D histograms of sensed nucleotides with respect to ionic current and dwell times for $\mathrm{dA}, \mathrm{dT}, \mathrm{dG}$ and 
dC. It can be observed that four DNA nucleotides can be distinctly detected with respect to ionic current; however minor dwell time overlapping is observed which may be due to low chemical specificity of solid-state nanopore sensing.

A customized algorithm (using MATLAB R2019b) was then employed to analyse the experimental data and predict the single nucleotide sequence obtained for 2-layers thick $\mathrm{MoS}_{2}$ pores. The sensed nucleotide sequence was then compared with the expected sequence (of the DNA oligo sample) to recognize the number and position of nucleotides not detected. The sensing efficiency was then evaluated from the fraction of the analyte DNA strands sensed. The algorithm analyses the sensing accuracy, detection rate, nucleotide specific mean current and current deviation. The predicted sequence compared with expected oligo sequence are displayed in Figure 4.a. The results clearly show that the analyte DNA is sequenced with high accuracy, as calculated from the few undetected nucleotides obtained (indicated in yellow in Figure 4.a). Thus, based on this on this the single nucleotide sensing accuracy through 2-layers thick $\mathrm{MoS}_{2}$ nanopore for 3000 bases was therefore estimated by MATLAB to be about $90.22 \%$. Figure $4 . \mathbf{b}$ demonstrates both ionic current and dwell time-based determination and differentiation of individual DNA bases through 2-layers thick $\mathrm{MoS}_{2}$ pores. A 6-33 \% current deviation is observed for 4-layers thick $\mathrm{MoS}_{2}$ pores, whereas a 2-11\% current deviation is observed for 2-layers thick $\mathrm{MoS}_{2}$ asserting a more efficient single nucleotide detection through 2-layers thick pores. (see Figure 5). 


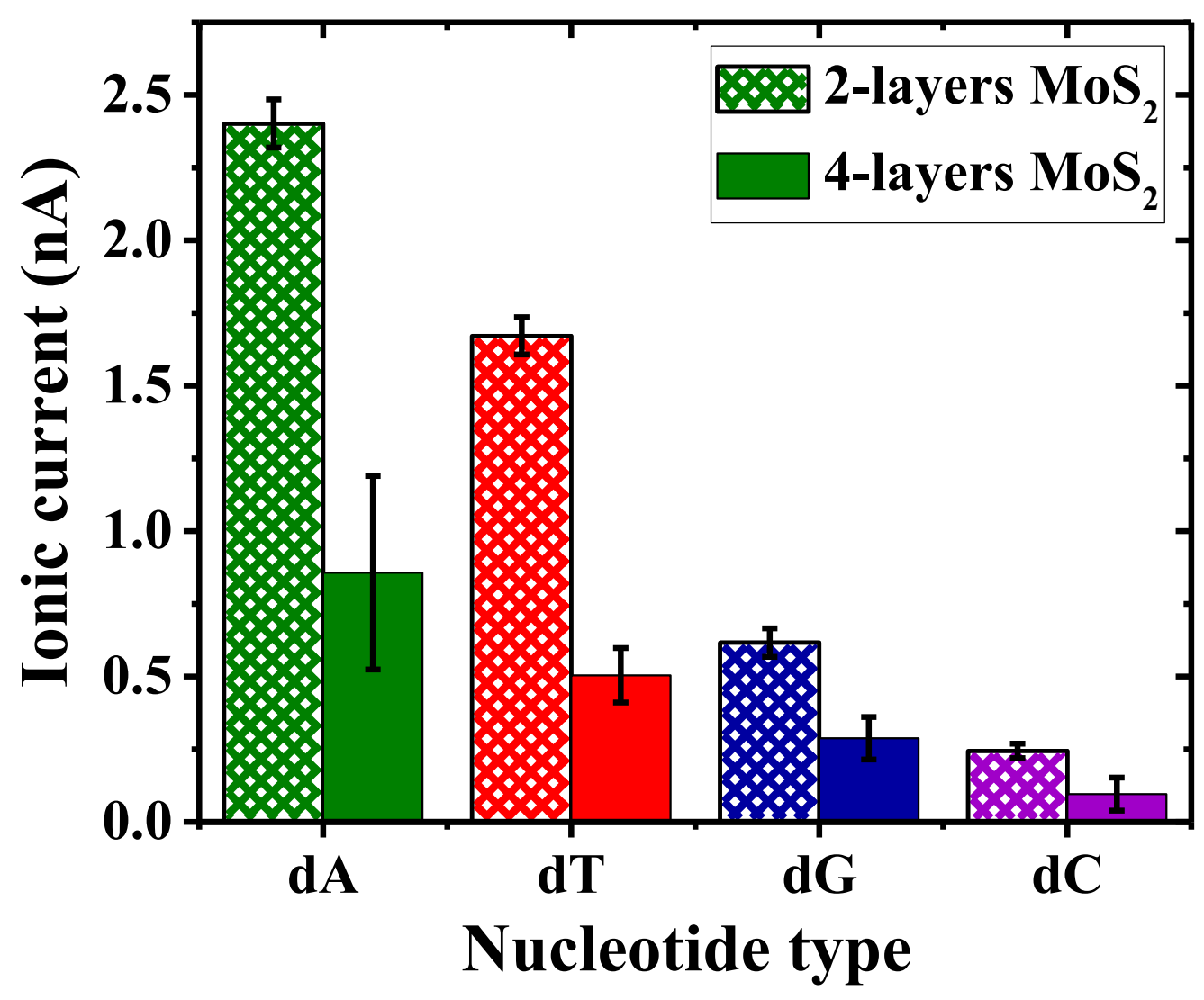

Figure 5. Ionic current signal magnitudes and deviation for different DNA nucleotides showing high signal accuracy displayed by 2-layers as compared to 4-layers thick $\mathrm{MoS}_{2}$ pores. The standard deviation (6-33\% for 4-layers thick $\mathrm{MoS}_{2}$ pores and 2-11\% for 2-layers thick $\mathrm{MoS}_{2}$ pores) reported here is from measurements on 7 pores.

The higher signal deviation for 4-layers thick $\mathrm{MoS}_{2}$ may be contributed to simultaneous detection of multiple nucleotides due to increased membrane thickness. The influence of surrounding molecules alters the specific signals by shifting baseline and also changing resultant charge interactions. The results summarize that interlayer potential gradient, suitable thickness compared to nucleotide dimension, good ionic current and dwell-time resolution makes 2-layers thick $\mathrm{MoS}_{2}$ 
a good choice for label-free unfunctionalized solid-state sensing of single DNA bases at picomolar concentration with high sensitivity.

Table 3: Summary of nanopore sequencing results using solid-state $\mathrm{SiN}_{\mathrm{x}}$ and $\mathrm{MoS}_{2}$ nanopores from literature along with our results. The table summarizes the material of the pore, thickness and size and the DNA type and concentrations used along with the signal to noise ratio and accuracy of nucleotide detection.

\begin{tabular}{|c|c|c|c|c|c|c|c|}
\hline Literature & $\begin{array}{l}\text { Nanopore } \\
\text { material }\end{array}$ & $\begin{array}{l}\text { Membrane } \\
\text { thickness }\end{array}$ & $\begin{array}{l}\text { Pore } \\
\text { size }\end{array}$ & DNA type & $\begin{array}{l}\text { DNA } \\
\text { concentration }\end{array}$ & $\begin{array}{l}\mathrm{S} / \mathrm{N} \\
\text { ratio }\end{array}$ & $\begin{array}{l}\text { Accuracy } \\
(\%)\end{array}$ \\
\hline $\begin{array}{l}\text { Liu et al., } \\
2014^{[19]}\end{array}$ & $\mathrm{MoS}_{2}$ & $0.65 \mathrm{~nm}$ & $\begin{array}{l}2.8 \\
\mathrm{~nm}\end{array}$ & $\begin{array}{l}\text { DNA } \\
\text { homopolymers }\end{array}$ & $\begin{array}{l}0.02 \mathrm{umol} / \mathrm{ml} \\
(20 \mathrm{uM})\end{array}$ & $>10$ & - \\
\hline $\begin{array}{l}\text { Feng et al., } \\
2015^{[14]}\end{array}$ & $\mathrm{MoS}_{2}$ & $0.65 \mathrm{~nm}$ & $\begin{array}{l}20 \\
\mathrm{~nm}\end{array}$ & pNEB plasmid & $0.5 \mathrm{nM}-6 \mathrm{nM}$ & $>10$ & 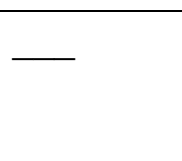 \\
\hline $\begin{array}{l}\text { Wanunu et } \\
\text { al. } 2010^{\text {[47] }}\end{array}$ & $\mathrm{SiN}_{\mathrm{x}}$ & $7 \mathrm{~nm}$ & $3 \mathrm{~nm}$ & $\begin{array}{l}\text { Hybridized } \\
\text { miRNA }\end{array}$ & $\begin{array}{l}1 \mathrm{fmol} / \mathrm{ul} \text { (1 } \\
\mathrm{nM})\end{array}$ & 46 & $93 \%$ \\
\hline $\begin{array}{l}\text { Atas et al., } \\
2012 \text {, } \\
\text { McNally et } \\
\text { al., } 2010 \text { [48- } \\
49]\end{array}$ & $\mathrm{SiN}_{\mathrm{x}}$ & $30 \mathrm{~nm}$ & $\begin{array}{l}3-5 \\
\mathrm{~nm}\end{array}$ & $\begin{array}{l}\text { Hybridized } \\
\text { DNA (Cyclic } \\
\text { DNA } \\
\text { conversion) }\end{array}$ & $100 \mathrm{nM}$ & & $\sim 90 \%$ \\
\hline Our work & $\mathrm{MoS}_{2}$ & $1.3 \mathrm{~nm}$ & $\begin{array}{l}2.8 \\
\mathrm{~nm}\end{array}$ & ssDNA oligos & $40 \mathrm{pM}$ & $>11$ & $\sim 90 \%$ \\
\hline
\end{tabular}


Few studies have been performed in determining nucleotide type and order in DNA strand containing mixed bases by using an unfunctionalized solid-state nanopore ${ }^{[15-19]}$. Read accuracy obtained in our work is similar to what is obtained by Atas et al. ${ }^{[48]}$ and McNally et al. ${ }^{[49]}$ Wanunu et al. (2010) ${ }^{[47]}$ demonstrated miRNA sequencing at $1 \mathrm{fmol} \mu \mathrm{l}^{-1}(1 \mathrm{nM})$ analyte concentration, by exploiting signal resolution improvement offered by small and thin nanopores $(3 \mathrm{~nm}$ diameter pores on $7 \mathrm{~nm}$ thick $\mathrm{SiN}_{\mathrm{x}}$ membranes). Wanunu et al. (2010) ${ }^{[47]}$ obtained $93 \%$ accuracy for RNA nucleobase sensing using complementary strand hybridized to the analyte strand. Thus, from the table it can clearly be seen that our 2-layers thick $\mathrm{MoS}_{2}$ nanopores with a diameter less than $3 \mathrm{~nm}$ demonstrates high sensitivity (comparable with that obtained in literature- see Table 3) at low DNA concentrations of $40 \mathrm{pM}$ even without the use of any analyte tags or additional biochemical functionalization.

\section{Experimental detail}

\section{Fabrication of $\mathrm{MoS}_{2}$ nanopores}

For fabricating $\mathrm{SiN}_{\mathrm{x}}$ membranes double-sided LPCVD (low stress) silicon nitride coated 4 inch, $525 \pm 25 \mu \mathrm{m},<100>$ silicon wafers were purchased from Rogue Valley Microdevices. For $\mathrm{MoS}_{2}$ membranes low defect density highly oriented $2 \mathrm{H}$ - phase single crystal was used which was procured from 2D semiconductors inc. Single-stranded DNA oligos with 25.5 n-moles (of a cutomized nucleotide sequence without any end functionalization) containing 30 mixed nucleotides in $250 \mu \mathrm{l}$ solution was procured from idtdna.com. All of the other reagents were obtained from Fisher Scientific. Solid-state free-standing $\mathrm{SiN}_{\mathrm{x}}$ membrane was fabricated using microfabrication techniques like lithography and etching (dry and wet). The $\mathrm{MoS}_{2}$ nanopores were fabricated by starting with the free standing $\mathrm{SiN}_{\mathrm{x}}$ membrane as substrate. A $200 \mathrm{~nm}$ diameter hole 
was patterned at the center of the membrane by EBL followed by Reactive Ion Etching (RIE). Then, 2-layers $(\sim 1.3 \mathrm{~nm})$ and 4-layers $(\sim 2.5 \mathrm{~nm})$ thick $\mathrm{MoS}_{2}$ flakes were mechanically exfoliated (scotch-tape) on the $200 \mathrm{~nm}$ diameter hole to form the free standing $\mathrm{MoS}_{2}$ membrane using a dual stage microscope for better alignment and centering. Size of $\mathrm{MoS}_{2}$ flakes were found to be around $20 \mu \mathrm{m}$ repeatedly. Then the nanopore was drilled on top by JEOL JEM-ARM200CF Scanning/ Transmission Electron Microscope (S/TEM). We were able to obtain pores in the size range of 2$4 \mathrm{~nm}$ diameter repeatedly based on our application requirement. Vigorous imaging on the same pore is avoided to prevent pore expansion due to prolonged beam exposure. Maintaining a good control over fabrication parameters we could achieve pores with an error of about $1-2 \mathrm{~A}^{0}$ in diameter, every time. The steps of fabrication for both membrane materials are given in Figure S5.a (see Figure S6 for the experimental images of fabrication steps).

\section{Reagent preparation}

$300 \mathrm{mM}$ filtered $\mathrm{KCl}$ solution was prepared and buffered with $3 \mathrm{mM}$ Tris- $\mathrm{HCl}$ was prepared $(\mathrm{pH}=8)$ and stored (to be used for measurement of ionic conductance). The latter solution was then diluted by DI water to $100 \mathrm{mM}$ for picomolar concentration analyte translocation experiments. The stored $\mathrm{KCl}$ solution was degassed for 90 minutes in vacuum. Before experiments, the temperature of degassed $\mathrm{KCl}$ was ensured to be at room temperature. Analyte solutions at $40 \mathrm{pM}$ concentration was prepared by repeated dilution of $8 \mu 1$ of purchased DNA solution.

\section{Custom-designed cell assembly and cleaning}

Half cells made of Poly-tetra-fluoro-ethylene (Teflon) were used as electrolytic chambers. Teflon having a good electro-chemical resistance and hydrophobicity helps maintain clean and insulated environment, required for accurate sensing. Polydimethylsiloxane (PDMS) gaskets were used to 
seal the half cells in order to prevent cross flow of electrolyte in between cells other than through nanopore. PDMS gaskets reduce capacitive noise during ionic current measurements. Sonicationassisted thorough cleaning of half cells was done before each experiment to remove any $\mathrm{KCl}$ residue. Bias across the membrane was applied using $\mathrm{Ag} / \mathrm{AgCl}$ electrodes dipped in the electrolyte contained in the half cells. Electrodes were functionalized with chloride by treating them with ethanol, DI water and dipping them in bleach for about 1 hour. Electric interference was prevented by isolating the entire assembly in a Faraday cage purchased from Warner instruments. For ionic current measurements both the cell chambers were filled with $0.3 \mathrm{M} \mathrm{KCl}$ solution. Figure S5.b of Supplementary information shows the experimental setup used for all experiments. Single channel recordings were obtained to characterize the solid-state nanopores. The ionic blockades induced by translocating DNA nucleotides were filtered by $2 \mathrm{kHz} 8$-pole Bessel filter, amplified by Axopatch 700B and finally digitized by Digidata 1550B.

Ionic current through the nanopore was measured at voltage swept from $-200 \mathrm{mV}$ to $200 \mathrm{mV}$ to measure the ionic conductance. Each pore was measured 7 times to obtain a stable conductance after repeated cleaning and the average conductance starting from the third measurement was reported.

\section{Pore Cleaning and mounting}

The membranes are cleaned three times by pulling acetone under vacuum for 30 minutes each, with the acetone solution being replaced by a new solution every time to avoid drying up of acetone at the nanopore. Then the same process is repeated four times using IPA and once using ethanol, each cycle was carried out for 20 minutes. During initial measurements, 4 cycles of IPA clean was found to be optimum for removing all acetone and achieve a low noise level by avoiding residues. 
Before experiments, the nanopore immersed in stored degassed $\mathrm{KCl}$ was electrically conditioned at constant $100 \mathrm{mV}$ voltage till the noise level is reduced to an accepted minimum.

\section{Conclusion}

In this study, we have conducted detailed simulation and experimental work to understand the behaviour of different number of layers of 2D material like $\mathrm{MoS}_{2}$ for its application in nanopore fabrication and sensing. Both our simulation and experimental studies clearly indicate that the multilayer thick $\mathrm{MoS}_{2}$ nanopore shows better sensitivity than a single layer one. It is clearly observed that even number of layers as the interlayer coupling potential provides increased electrophoretic pull. We observe that the 2-layers thick $\mathrm{MoS}_{2}$ nanopore displays greater single nucleotide detection accuracy of $\sim 90 \%$ with signal to noise ratio greater than 11 at 40 pM DNA concentrations compared to 4-layers. Thus, we have conclusively demonstrated a high accuracy and signal to noise ratio for 2-layers thick $\mathrm{MoS}_{2}$ nanopores with diameters less than $3 \mathrm{~nm}$ without any functionalization for analyte concentrations as low as $40 \mathrm{pM}$. It can thus be concluded that 2D materials like $\mathrm{MoS}_{2}$ can be tuned to obtain high quality nanopores for ultra-sensitivity and accuracy which can be utilised effectively for nanopore applications for detection of low concentration analytes.

\section{Reference}

[1] J. J. Kasianowicz, J. J., Brandin, E., Branton, D. \& Deamer, D. W., Characterization of individual polynucleotide molecules using a membrane channel. PNAS. 93, 13770 (1996).

[2] Haque, F., Li, J., Wu, H. C., Liang, X. J. \& Guo, P. Solid-State and Biological Nanopore for Real-Time Sensing of Single Chemical and Sequencing of DNA. Nano Today., 8, 56 (2013). 
[3] Sawafta, F., Carlsen, A. T. \& Hall, A. R., Membrane Thickness Dependence of Nanopore Formation with a Focused Helium Ion Beam. Sensors (Switzerland), 14, 8150 (2014).

[4] Lanyon, Y. H., Marzi, G. D., Watson, Y. E., Quinn, A. J., Gleeson, J. P., Redmond, G., M \& Arrigan, D. W. Fabrication of Nanopore Array Electrodes by Focused Ion Beam Milling. Anal. Chem., 79, 3048 (2007).

[5] Kim, H. M., Lee, M. H. \& Kim, K. B. Theoretical and experimental study of nanopore drilling by a focused electron beam in transmission electron microscopy. Nanotechnology, 22, 275303 (2011).

[6] Deng, Y., Huang, Q., Zhao, Y., Zhou, D., Ying, C. \&Wang, D. Precise fabrication of a 5 nm graphene nanopore with a helium ion microscope for biomolecule detection. Nanotechnology, 28, 045302 (2017).

[7] Zahid, O. K. \& Hall, A. R. Helium Ion Microscopy. NanoScience and Technology, Springer, Cham, 2016, 447; ISBN: 978-3-319-41988-6.

[8] Liu, K., Chao, P., Alexandre, K., Adrian, P. N., Georg, E. F., Olgica, M. \& Aleksandra, R., Detecting topological variations of DNA at single-molecule level. Nature Communications, 10, Article number: 3 (2019).

[9] Wanunu, M., Sutin, J., McNally, B., Chow, A \& Meller, A. DNA Translocation Governed by Interactions with Solid-State Nanopores. Biophys. J., 95, 4716 (2008).

[10] Gusella, J. F., et al. A polymorphic DNA marker genetically linked to Huntington's disease. Nature, 306, 234 (1983).

[11] Dina, N. E., Colnita, A., Leopold, N. \& Haisch, C. Rapid Single-cell Detection and Identification of Bacteria by Using Surface-enhanced Raman Spectroscopy. Procedia Technology, 27, 203 (2017).

[12] Barhoumi, A., Zhang, D., Tam, F. \& Halas, N. J. Surface-Enhanced Raman Spectroscopy of DNA. J. Am. Chem. Soc., 130, 5523 (2008).

[13] Freedman, K. J., Otto, L. M., Ivanov, A. P., Barik, A., Oh, S. H. \& Edel, J. B. Nanopore sensing at ultra-low concentrations using single-molecule dielectrophoretic trapping. 
Nature Communications, 7, Article number: 10217 (2016).

[14] Feng, J., Liu, K., Bulushev, R. D., Khlybov, S., Dumcenco, D., Kis, A. \& Radenovic, A. Nat. Nanotechnol., 10, 1070 (2015).

[15] Li, J., Gershow, M., Stein, D., Brandin, E. \& Golovchenko, J. Identification of single nucleotides in MoS2 nanopores. Nat. Mater., 2, 611 (2003).

[16] Fologea, D., Gershow, M., Ledden, B., McNabb, D. S., Golovchenko, J. A. \& Li, J. Detecting Single Stranded DNA with a Solid State Nanopore. Nano Lett. 5, 1905 (2005).

[17] Schneider, G. F., Kowalczyk, S. W., Calado, V. E., Pandraud, G., Zandbergen, H. W., K. Vandersypen, L. M. \& Dekker, C. DNA Translocation through Graphene Nanopores. Nano Lett., 10, 3163 (2010).

[18] Merchant, C. A., et al. DNA Translocation through Graphene Nanopores. Nano Lett., 10, 2915 (2010).

[19] Liu, K., Feng, J., Kis, A. \& Radenovic, A. Atomically Thin Molybdenum Disulfide Nanopores with High Sensitivity for DNA Translocation. ACS Nano., 8, 2504 (2014).

[20] Sessa, F., Salerno, M., Bertozzi, G., Messina, G., Ricci, P., Ledda, C., Rapisarda, V., Cantatore, S., Turillazzi, E. \& Pomara, C. Touch DNA: impact of handling time on touch deposit and evaluation of different recovery techniques: An experimental study. Sci Rep. 9, 9542 (2019).

[21] Pinhasi, R., et al. Optimal Ancient DNA Yields from the Inner Ear Part of the Human Petrous Bone. PLOS ONE, 10, e0129102 (2015).

[22] Gu, W., Miller, S. \& Chiu, C. Y. Clinical Metagenomic Next-Generation Sequencing for Pathogen Detection. PMC, 14, 319 (2019).

[23] Bos, K. I., Jäger, G., Schuenemann, V. J., Vågene, A. J., Spyrou, M. A., Herbig, A., Nieselt, K. \& Krause, J. Ancient DNA: the first three decades. Philos Trans R Soc Lond B Biol Sci., 370, 20130375 (2015).

[24] Clancy, S. Genetic Mutation. Nature Education, 1, 187 (2008).

[25] Feng, Y., Zhang, Y., Ying, C., Wang, D. \& Du, C. Nanopore-based fourth-generation DNA 
sequencing technology. Genomics, Proteomics and Bioinformatics, 13, 4 (2015).

[26] Li, J., Wang, H., Li, Y. \& Han, K. The impact of the number of layers of the graphene nanopores and the electrical field on ssDNA translocation. Molecular Simulation, 43, 320 (2017).

[27] Agah, S., Zheng, M., Pasquali, M. \& Kolomeisky, A. B. DNA sequencing by nanopores: advances and challenges. J. Phys. D. Appl. Phys., 49, 413001 (2016).

[28] Yanagi, I., Ishida, T., Fujisaki, K. \& Takeda, K. I. Fabrication of 3-nm-thick Si3N4 membranes for solid-state nanopores using the poly-Si sacrificial layer process. Sci. Rep., 5, 14656 (2015).

[29] Liu, K., Lihter, M., Sarathy, A., Caneva, S., Qiu, H., Deiana, D., Tileli, V., Alexander, D. T. L., Hofmann, S., Dumcenco, D., Kis, A., Leburton, J. P. \& Radenovic, A. Geometrical Effect in 2D Nanopores. Nano Lett., 17, 4223 (2017).

[30] Chen, W., Liu, G. C., Ouyang, J., Gao, M. J., Liu, B. \& Di Zhao, Y. Graphene nanopores toward DNA sequencing: a review of experimental aspects. Science China Chemistry. 60, 721 (2017).

[31] Arjmandi-Tash, H., Belyaeva, L. A. \& Schneider, G. F. Single molecule detection with graphene and other two-dimensional materials: nanopores and beyond. Chem. Soc. Rev., $\mathbf{4 5 ,}$ 476 (2016).

[32] Schneider, G. F., Xu, Q., Hage, S., Luik, S., Spoor, J. N. H., Malladi, S., Zandbergen, H. \& Dekker, C. Tailoring the hydrophobicity of graphene for its use as nanopores for DNA translocation. Nature Communications, 4, 2619 (2013).

[33] Carral, A. D., Sarap, C. S., Liu, K., Radenovic, A. \& Fyta, M. 2D MoS2 nanopores: ionic current blockade height for clustering DNA events. 2D Mater., 6, 045011 (2019).

[34] Ke, J. A., Garaj, S. \& Gradečak, S. Nanopores in 2D MoS2: Defect-Mediated Formation and Density Modulation. ACS Appl. Mater. Interfaces, 11, 26228 (2019).

[35] Nicolaï, A., Pérez, M. D. B., Delarue, P., Meunier, V., Drndić, M. \& Senet, P. Molecular Dynamics Investigation of Polylysine Peptide Translocation through MoS2 Nanopores. J. 
Phys. Chem. B. 123, 2342 (2019).

[36] Graf, M., Lihter, M., Thakur, M., Georgiou, V., Topolancik, J., Ilic, B. R., Liu, K., Feng, J., Astier, Y. \& Radenovic, A. Fabrication and practical applications of molybdenum disulfide nanopores. Nature Protocols, 14, 1130 (2019).

[37] Shim, J., Banerjee, S., Qiu, H., Smithe, K. K. H., Estrada, D., Bello, J., Pop, E., Schultenf K. \& Bashir, R. Detection of methylation on dsDNA using nanopores in a MoS2 membrane. Nanoscale, 9, 14836 (2017).

[38] Mereuta, L., Roy, M., Asandei, A., Lee, J. K., Park, Y., Andricioaei, I. \& Luchian, T. Slowing down single-molecule trafficking through a protein nanopore reveals intermediates for peptide translocation. Sci. Rep., 4, 3885 (2015).

[39] Luan, B., Stolovitzky, G. \& Martyna, G. Slowing and controlling the translocation of DNA in a solid-state nanopore. Nanoscale, 4, 1068 (2012).

[40] Melnikov, D. V., Leburton, J. P. \& Gracheva, M. E. Slowing down and stretching DNA with an electrically tunable nanopore in a p-n semiconductor membrane. Nanotechnology, 23, 255501 (2012).

[41] Akahori, R., Haga, T., Hatano, T., Yanagi, I., Ohura, T., Hamamura, H., Iwasaki, T., Yokoi, T. \& Anazawa, T. Slowing single-stranded DNA translocation through a solid-state nanopore by decreasing the nanopore diameter. Nanotechnology, 25, 75501 (2014).

[42] Waugh, M., Carlsen, A., Sean, D., Slater, G. W., Briggs, K., Wok, H. K. \& Tabard-Cossa, V. Interfacing solid-state nanopores with gel media to slow DNA translocations. Electrophoresis, 36, 1759 (2015).

[43] He, Y., Tsutsui, M., Scheicher, R. H., Fan, C., Taniguchi, M. \& Kawai, T. Mechanism of how salt-gradient-induced charges affect the translocation of DNA molecules through a nanopore. Biophys. J., 105, 776 (2013).

[44] Ganatra, R. \& Zhang, Q. Few-Layer MoS2: A Promising Layered Semiconductor. ACS Nano., 8, 4074 (2014).

[45] Feng, J., Liu, K., Graf, M., Lihter, M., Bulushev, R. D., Dumcenco, D., Alexander, D.T.L., 
Krasnozhon, D., Vuletic, T., Kis, A. \& Radenovic, A. Electrochemical Reaction in Single Layer MoS2: Nanopores Opened Atom by Atom. Nano Lett., 15, 3431 (2015).

[46] Bard, A. J. \& Faulkner, L. R. Electrochemical Methods: Fundamentals and Applications. Electrochemical Methods, Second edition, Department of Chemistry and Biochemistry, University of Texas, Austin, 2001.

[47] Soon, J. M. \& Lohz, K. P. Electrochemical Double-Layer Capacitance of MoS2 Nanowall Films. Electrochemical and Solid-State Letters, 2007, 10, A250.

[48] Atlas, E., Singer, A. \& Meller, A. DNA sequencing and bar-coding using solid-state nanopores. Electrophoresis, 2012, 33, 3437.

[49] McNally, B., Singer, A., Yu, Z., Sun, Y., Weng, Z. \& Meller, A. Optical recognition of converted DNA nucleotides for single-molecule DNA sequencing using nanopore arrays. Nanoletters, 10, 2237 (2010). 